\title{
The Effect of Motivation and Self-Efficacy on Math Studies in the Israeli Ministry of Education's Program "Give Five"
}

\author{
Nitza Davidovitch ${ }^{1} \&$ Roman Yavich $^{1}$ \\ ${ }^{1}$ Ariel University, Ariel, Israel \\ Correspondence: Nitza Davidovitch, Ariel University, Ariel, Israel. E-mail: d.nitza@ariel.ac.il
}

Received: November 5, 2018

Accepted: November 28, 2018

Online Published: December 3, 2018

doi:10.5430/ijhe.v7n6p63

URL: https://doi.org/10.5430/ijhe.v7n6p63

\begin{abstract}
Studying mathematics is an essential condition for acquiring an education in most fields such as all exact sciences, financial sphere, programming, etc. It enables students to choose from among a large variety of professions with significantly high chances of academic admission, mainly in fields such as engineering, natural sciences, and technology, as well as in a considerable part of the social sciences Hence, studying mathematics in high school is a critical and key factor for continued studies and for integration in many professions in the Israeli workforce. The current study sought to expand knowledge on the effect of students' psychological feelings, such as motivation and self-efficacy, in light of the "Give Five" reform initiated by the Ministry of Education implemented in 2015. The study examined the effects of the "Give Five" reform on student motivation and self-efficacy, while examining whether these influences were gender-dependent. The study confirmed a positive correlation between the degree of motivation to study mathematics and the level of self-efficacy, and no difference was found between males and females in their level of motivation and self-efficacy. Future recommendations include research into the significance of motivation and self-efficacy as a major determinant of scholastic success.
\end{abstract}

Keywords: motivation, self-efficacy, math studies, Israeli program, "give five"

\section{Introduction}

Studying mathematics is an essential condition for acquiring an education in most fields. It enables students to choose from a large variety of professions, and increases their chances of admission to academic studies, mainly in fields such as engineering, natural sciences, technology, and social sciences. Hence, studying mathematics in high school is a critical and key factor for continued studies and for integration in many professions in the Israeli workforce (Saunders, 1980; Sells, 1978). For this reason, educators and students view mathematics as an important academic field and invest in it much more time than in other disciplines, both because it is difficult to learn and because of its significance (Harris, Black, Hernandez-Martinez, Pepin, B \& Williams, 2015).

The issue of mathematical achievements in high school has repeatedly occupied those engaged in education. Teachers teaching in heterogeneous classrooms encountered difficulties as the class encompassed at time more than 5 different levels, (Mirza \& Hussain, 2014). The use of ability groupings allows the adaptation of contents, levels, pace, and instruction method to students who function on different levels (Dar \& Resh; Slavin, 1988, Mirza \& Hussain, 2014). Moreover, thought that teaching in groupings is a good way of dealing with the problems of disadvantaged students have and can lead to improvement of their scholastic achievements (Kahn, Linchevski \& Igra, 1995). In the 1960s the Ministry of Education supported learning in ability groupings in several major subjects: Hebrew, math, and English. From 1966 well established schools also began teaching in groupings. However it seems that these groupings were transformed into organizational settings with no added educational treatment and thus only intensified the existing disparities (Mukhanova \& Mukhanov, 2013)

During the last ten years many scientists (Mukhanova \& Mukhanov, 2013) compared the achievements of students in heterogeneous classrooms and of students in classrooms that study in groupings, and found that the achievements of the higher-ability students were similar when studying in groupings or in heterogeneous classrooms. In contrast, lower-ability students who studied in ability groupings attained lower achievements than those who studied with the rest of the class. A synthesis (Mirza \& Hussain, 2014) of 29 studies that examined junior high math achievements in ability groupings versus a frontal setting showed that ability groupings had little or no effect on math achievements. However, when relating to the interaction between the study method and the students' level, students in higher ability 
groupings reached higher achievements on average than students with similar abilities in a heterogeneous classroom, while medium- and low-ability students did worse on average than students with similar abilities in heterogeneous classrooms (Slavin, 1990).

Ability groupings seem to have a social price as well since they separate students hierarchically (Hornby \& Witte, 2014). In most cases, this separation is largely compatible with students' socioeconomic differences (Hornby \& Witte, 2014). Disadvantaged population groups are overly represented in lower ability levels (Chen, Levy \& Adler, 1978 (Hornby \& Witte, 2014). Segregation by ability groupings gives students different academic, social, and psychological experiences that might affect their achievements and aspirations further on in life (Hornby \& Witte, 2014). According to several scholars, schools that focus on tasks lead to improvement of the individual's potential, creativity, control, and willingness to cope with challenging tasks (Hornby \& Witte, 2014; Mukhanova \& Mukhanov, 2013). In contrast, schools that focus on ability might lead to negative competition, fear of failure, harm to one's self-esteem and thus also to motivation (Hornby \& Witte, 2014). Studying in ability groupings aggravates the problem of low motivation, which might worsen due to the sensitivity of junior high students in early adolescence to their image as perceived by others and their need for adult support outside the home (Hornby \& Witte, 2014).

\subsection{The "Give Five" Program}

On August 30, 2015, the Israeli Ministry of Education launched the program "Give Five - The national program for promotion of mathematics". As part of the program, the Ministry of Education enabled all high schools in Israel to provide enhanced math studies, with strict attention to academic standards. The target set by the ministry: to double the number of those studying for 5 matriculation units in 4 years to 18,000 students. As part of the program, the ministry enables all high schools to teach 5 matriculation units in math, and for this purpose the number of teachers was doubled and 100 new study tracks opened, some in small classrooms of only 6 students, with individual attention and a personally adapted study rate (Ministry of Education, 2015).

\subsection{Gender Differences}

In Israel, there is a large male-female discrepancy in enrollment for studies in mathematics-related fields in tertiary schools and universities (Zuzovsky, 2003) Gender differences in high school mathematics studies are a well-known phenomenon among teachers and educators and has been studied extensively, beginning from the 1970s(Amador, 2018; Yasar \& Metin, 2016). Studies show that from about age 14 girls reach lower math achievements than boys, and girls more than boys avoid taking high level math electives (Amador, 2018; Yasar \& Metin, 2016). As a result, when reaching tertiary education girls lack the mathematical readiness required in order to receive enrichment in technological subjects and the exact sciences and they enroll mainly for studies in nursing, the humanities, and the social sciences (Amador, 2018).

Studies have shown that schoolgirls feel less confident in their ability in mathematics and sciences and less interested in developing a career in science and engineering subjects than boys, (Amador, 2018; Yasar \& Metin, 2016) although they are exposed to the same proportion of lessons in these fields and although they do as well as boys (National Science Foundation, 1994). It has been reported that boys and girls on all school levels have a stereotypical image of scientists as being male (Amador, 2018). When boys and girls were given the option of choosing between a selection of science classes or other classes, boys chose science more than girls. When asked to choose classes for members of the other sex, girls chose more science lessons for boys and boys chose less science lessons for girls (Amador, 2018).

Nonetheless, there has been a gradual decrease in gender-based math disparities over the years (Hyde et al., 2008), both in average achievements and in the various measures reflecting the rate of outstanding students. For example, the rate of female students who received scores of more than 700 on the SAT exam in mathematics, compared to that of male students, rose from 13:1 in 1983 to 3:1 in 2000 (Brody \& Mills, 2005), and a constant rise is also evident in the proportion of women who earn a PhD in mathematics in the US (Burrelli, 2008).

\subsection{Motivation}

Having motivation means being motivated to do something (Alkaabi, Alkaabi \& Vyver, 2017). An individual who feels a lack of urge or inspiration to act is characterized by lack of motivation, while someone who is charged with energy or acts towards some end is considered motivated (Deci \& Ryan, 2000), Alkaabi, Alkaabi \& Vyver, 2017). In recent decades, recognition of the major role of motivation processes for students' success in their studies, as well as other processes of adjustment such as feelings towards learning and towards school, disruptive behavior in class, coping with difficulties and failure, and wellness in general, have been increasing (Butler, 1990; Schunk \& Pintrich, 1996; Alkaabi, Alkaabi \& Vyver, 2017). This recognition has risen concurrently with the development of theories and 
research programs aimed at understanding the motives and processes that underlie students' behavior at school. An important goal of these theories and studies is their implementation in situations where students' motivation is not optimal. There have been many attempts and considerable success in operating programs aimed at encouraging and promoting students' motivation at school (Kaplan, Katz \& Roth, 2000; Midgley \& Meahr, 1996; Alkaabi, Alkaabi \& Vyver, 2017)

\subsection{Learning Motivation}

The concept of learning motivation has received extensive research attention in recent decades (Libao, Sagun, Tamangan, Pattalitan, Dupa \& Bautista, 2016). A student's scholastic achievements are greatly affected by his or her level of motivation to study and to persevere in the educational system (Libao, Sagun, Tamangan, Pattalitan, Dupa \& Bautista, 2016). The most common empirical indicators of motivation are measures of students' educational expectations and aspirations. The assumption underlying these measures is, on one hand, that a student who strives to reach a high level of education has the necessary motivation to do so, and on the other, that a student with high motivation will express a high level of aspirations (Libao, Sagun, Tamangan, Pattalitan, Dupa \& Bautista, 2016). A positive association was found between learning motivation and actual study performance (Alkaabi, Alkaabi \& Vyver, 2017; Libao, Sagun, Tamangan, Pattalitan, Dupa \& Bautista, 2016). For example, in a meta-analysis that examined the correlations between scholastic success, psychosocial variables, and ability variables, "motivation to achieve" in the context of studies, defined as motivation to succeed, enjoying overcoming obstacles, completing tasks, and being motivated to succeed and excel, predicted students' grades (Roobbins, Lauver, Lauver, Davis, Langley \& Carlstrom, 2004).

The researchers (Libao, Sagun, Tamangan, Pattalitan, Dupa \& Bautista, 2016) examined the effect of learning motivation on the association between ability and study performance among school children. They explored academic ability, actual performance, and motivation, using a designated questionnaire. Learning motivation was found to modify the association between ability and performance among the students, such that among the highly motivated a higher correlation was found between scholastic ability and actual grades, indicating higher realization of their scholastic potential (Libao, Sagun, Tamangan, Pattalitan, Dupa \& Bautista, 2016).

It is possible to distinguish between different types of academic motivation: lack of motivation - a concept similar to that of "learned helplessness", which reflects the inner experience of having no motivation to learn, and thus learning is experienced as something that is not done willingly (Alkaabi, Alkaabi \& Vyver, 2017; Libao, Sagun, Tamangan, Pattalitan, Dupa \& Bautista, 2016). Inner motivation - learning for the enjoyment and sense of satisfaction generated, and in contrast external motivation - learning in order to gain a profit or to avoid harm (Libao, Sagun, Tamangan, Pattalitan, Dupa \& Bautista, 2016) .

Studies based on the division into these types of motivation indicate that inner motivation has a major positive effect on scholastic success, as supported by laboratory studies that point to a causal relationship between inner motivation and successful performance in practice (Alkaabi, Alkaabi \& Vyver, 2017; Libao, Sagun, Tamangan, Pattalitan, Dupa \& Bautista, 2016).

In summary, these studies, which examined the association between learning motivation, early academic ability, and academic performance, found both direct correlations and combined effects of early ability and academic motivation on performance.

\subsection{Self-Efficacy}

The term self-efficacy was generated by Bandura's (1977) Theory of Social Learning. The definition of self-efficacy is the belief that one can successfully perform a certain behavior that is needed in order to produce a result. Self-efficacy changes how people think, feel, and act. People with high self-efficacy tend to rely more on their abilities when encountering obstacles, tend to conceptualize problems as challenges rather than threats, experience less negative emotional arousal during stressful tasks, think in an empowering and motivational way, and display persistence when coping with difficult situations (Cave, Evans, Dewey \& Hartshorn, 2018). The degree in which people perceive themselves as having self-efficacy will determine whether they will initiate action, how much effort they will invest, and how long they will persist in performing that action even when encountering obstacles and negative experiences. The higher the perceived self-efficacy, the greater the efforts (Bandura, 1977). There are four main sources of self-efficacy, which in turn affect one's behavior and performance. The first component is mastery experience and it has the greatest weight in the composition of self-efficacy. Multiple experiences of success raise one's sense of self-efficacy, while recurring experiences of failure reduce the sense of self-efficacy. Once a strong sense of self-efficacy is formed following recurring experiences of success, the effect of a small number of failures will be 
smaller (Bandura, 1977; Bandura, 1982). Experiencing a small number of failures, which one later manages to overcome through constant efforts, can strengthen self-motivation and persistence if the person finds, through his or her experience, that it is possible to overcome even the most difficult obstacles. Hence, the effect of failures on self-efficacy partially depends on the timing and on the overall pattern of the experiences that included failure (Bandura, 1977).

The second source of self-efficacy is vicarious experience and it is based on the process of social learning (Bandura, 1977). People can develop a sense of self-efficacy indirectly by watching others take action successfully or unsuccessfully. Watching others perform threatening actions with no negative implications can create in the observer expectations of self-improvement predicated on persistence and greater efforts. In contrast, watching others fail in a task can reduce that person's sense of self-efficacy. These assumptions are particularly true when people see themselves as similar to others being observed (Bandura, 1977).

The third source relates to verbal persuasion. This is the most common source as it is readily available and easy to use and refers to verbal persuasion of a person regarding his or her abilities or persuasion regarding the person's inability to perform a certain action. In this way, verbal persuasion can either raise or lower one's sense of self-efficacy. Expectations of self-efficacy that are produced by this source are usually weaker than those produced by the experience of successful performance, as in this case there is no authentic experience underlying the expectation. Therefore, when one is in an anxiety-generating situation and has a history of recurring failures, expectations of self-efficacy resulting from verbal persuasion will be rapidly overshadowed by the person's past experiences of failure (Bandura, 1977).

The last source of self-efficacy is physiological arousal. Information on the ability to cope is also derived from physiological arousal. Bandura (1977) claimed that the way in which one interprets his or her physiological arousal may affect the person's sense of self-efficacy. Hence, it is more likely that one will develop higher efficacy expectations when he or she manages to overcome negative arousal than when anxious and tense.

\subsection{Generalized Self-Efficacy}

The concept of generalized self-efficacy was developed by Jerusalem and Schwarzer (1992) and reflects a general reference to one's ability to cope with a wide range of situations. According to Bandura (1977), self-efficacy has good predictability only when it is evaluated with regard to a specific ability and a specific context, i.e., task-specific self-efficacy. In contrast, studies suggest that several experiences of failure or success in a certain area can lead to evaluation of domain-specific self-efficacy (Cave, Evans, Dewey \& Hartshorn, 2018).

Evaluations of self-efficacy with regard to various domains over a lengthy period of time may lead to general confidence in one's ability to cope with a wide range of stressful or new situations. This general confidence may be referred to as stable general self-efficacy (Hendy, Lyons \& Breakwell, 2006).

\subsection{Learning Self-Efficacy}

In the field of education, self-efficacy has been investigated mainly with regard to its prediction of academic achievements (Khasawneh \& Bates, 2007) and with regard to its effect on choosing an academic discipline and vocational specialty (Labone, 2007). Self-efficacy has been found related to several key concepts of learning motivation: self-concept, optimism, achievement- and goal-orientation, and test anxiety (Hutchison, Follman, Sumpter \& Bodner, 2006). Students with high self-efficacy evaluate their academic work as more efficient, solve problems more efficiently, and have higher persistence capacity than students with low self-efficacy. In addition, they also work better at their tasks, criticize their progress more often, and utilize self-regulation strategies that improve their success (Pajares \& Schunk, 2005).

\subsection{The Current Study}

The "Give Five" reform, initiated by the Ministry of Education, is a new reform introduced to address the issue of enhancing the study of math units for the matriculation exam. The reform was evaluated and was deemed a success. The purpose of this study is to examine the effects of the reform on motivation level and self-efficacy levels and to explore whether these effects are gender-differentiated. The uniqueness of the study is in its ability to try and analyze the effects of the reform, and the current findings can in the future serve as a tool for analyzing the outcomes of the reform and for developing prospective long-term programs. Another unique aspect of this study is the attempt to establish an association between academic programs and subjective psychological variables such as those examined in the study, which has not been achieved to date.

The purpose of the current study is to examine the effect of the "Give Five" reform on the research variables of motivation and self-efficacy, hypothesizing that: 
1. A positive correlation will be found between the level of motivation to study mathematics, and the level of self-efficacy.

2. The gender variable will constitute an intervening variable for the research variables, such that differences will be found between male and female students both in levels of motivation and in levels of self-efficacy.

3. Differences will be found in the level of motivation and self-efficacy by number of matriculation units in mathematics, such that the higher the number of units the more positive the correlation with data on self-efficacy and motivation.

\section{Method}

The study comprised 120 students, 60 male (50\%) and 60 female (50\%), in the 15-19 age range $(M=16.69, S D=0.63)$. Of all male students, 39 were in the tenth grade (32.5\%), 78 in the eleventh grade $(65 \%)$, and 3 in the twelfth grade $(2.5 \%)$. These grade levels were chosen since matriculation exams in mathematics are administered in these grades only. With regard to mathematics, 33 were studying for the 3-unit matriculation exam (27.5\%), 39 for the 4-unit exam $(32.5 \%)$, and 48 for the 5-unit exam (40\%). An absolute majority were Israelis $(97.5 \%)$. The geographical location of the respondents was relatively homogeneous. The male students were studying at a high school in the city of Modi'in and resided in this and adjacent towns. The female students were from Ulpanat Lehava in Kdumim and resided locally and in adjacent towns.

\subsection{Procedure}

The participants engaged with the experiment in their high school classroom. The questionnaires were administered personally to each respondent and the study was anonymous. After a short presentation and explanation of the research procedure and purpose, participants interested in taking part in the study signed an informed consent form, completed a demographic questionnaire, and answered a questionnaire on their level of generalized self-efficacy. Participants then received a motivation questionnaire. Completion of the various questionnaires took 15 minutes on average and was performed over a period of several weeks. The data were then entered in the SPSS software and statistical analysis of the data was carried out.

\subsection{Tools}

1. Questionnaire on demographic information and medical data - The questionnaire collects demographic information such as: sex, age, country of birth, marital status, and years of education. Students' personal background is important, particularly in Israel that is a multicultural country with central as well as more peripheral areas.

2. Questionnaire on generalized self-efficacy - Developed in 1997 by Chen and Gully (1997) and adapted by Chen, Gully \& Eden (2001). The questionnaire includes 8 questions examining learning self-efficacy, using a 3 -level Likert scale ( $1=$ not at all, $3=$ strongly). The current study yielded an internal reliability of $\alpha=.92$.

3. Questionnaire on learning motivation for students - Questionnaire examining learning motivation, based on the motivation questionnaire developed by Pintrich and DeGroot (1990). The questionnaire consists of 31 questions that explore learning motivation, using a 7-level Likert scale (1=completely untrue, 7 -very true). The study indicated deficient internal consistency and therefore it was necessary to detract one item (14). After this adjustment, excellent internal reliability was found (items $1-31 ; \alpha=.91$ ). Good internal reliability was found between the items that checked students' level of motivation as directly associated with Bennett's reform (items $32-34 ; \alpha=.82)$.

\section{Results}

The study aimed to explore the effect of the reform on motivation and on levels of self-efficacy, as well as to explore whether there are gender differences in these variables.

\subsection{Descriptive Statistics}

For descriptive statistics of the research variables among all respondents see Table 1 . The table shows that the mean score for self-efficacy was in the upper part of the scale, although the response was heterogeneous - indicating a high level of self-efficacy, though the mean does not truly reflect all respondents. It appears that the mean for general motivation was located slightly above the center of the scale, with the distribution of the data being homogeneous indicating a moderate-positive level of general motivation. Finally, it appears that the mean motivation associated with the reform was located slightly below the center of the scale, although the distribution of the data was heterogeneous indicating moderate-negative attitudes to the reform, although the mean does not truly reflect all respondents. 
Table 1. Means, standard deviations, minimum, and maximum, with regard to the research variables $(N=120)$

\begin{tabular}{|c|c|c|c|c|c|}
\hline & M & SD & Minimum & Maximum & $\begin{array}{l}\text { Original } \\
\text { scale }\end{array}$ \\
\hline Self-efficacy & 2.28 & 0.57 & 1.00 & 3.00 & $1-3$ \\
\hline General motivation & 4.54 & 0.98 & 2.57 & 6.52 & $1-7$ \\
\hline $\begin{array}{l}\text { Motivation associated } \\
\text { with the reform }\end{array}$ & 3.29 & 1.79 & 1.00 & 7.00 & $1-7$ \\
\hline
\end{tabular}

For a thorough report of students' attitudes to the reform, see Table 2. The table shows that the means of all attitudes are located below the center of the scale, and that the response to each of the statements was heterogeneous. The most significant distribution of data was received for the perception that the management and teachers demand more success on the 5-unit math level than in the past, followed by the view that the five unit reform is beneficial and improves personal achievements - showing that the largest variance in students' responses was found for these statements.

\subsection{Examination of the Research Hypotheses}

\subsubsection{First Research Hypothesis: Association between Motivation and Self-Efficacy}

The first research hypothesis posited that a positive association would be found between the level of motivation to study mathematics and the level of self-efficacy. In order to examine this hypothesis, a Pearson correlation matrix ( $\mathrm{r}_{\mathrm{p}}$ ) was calculated. For the matrix findings, see Table 3.

Table 3. Matrix of Pearson correlations between level of motivation and level of efficacy $(N=120)$

\begin{tabular}{lll} 
& General motivation & Motivation associated with the reform \\
\hline Self-efficacy & $.81 * * *$ & $.34 * * *$ \\
\hline$* * * \mathrm{p}<.001$ &
\end{tabular}

Table 3 shows an association between the level of motivation to study mathematics and the level of self-efficacy.

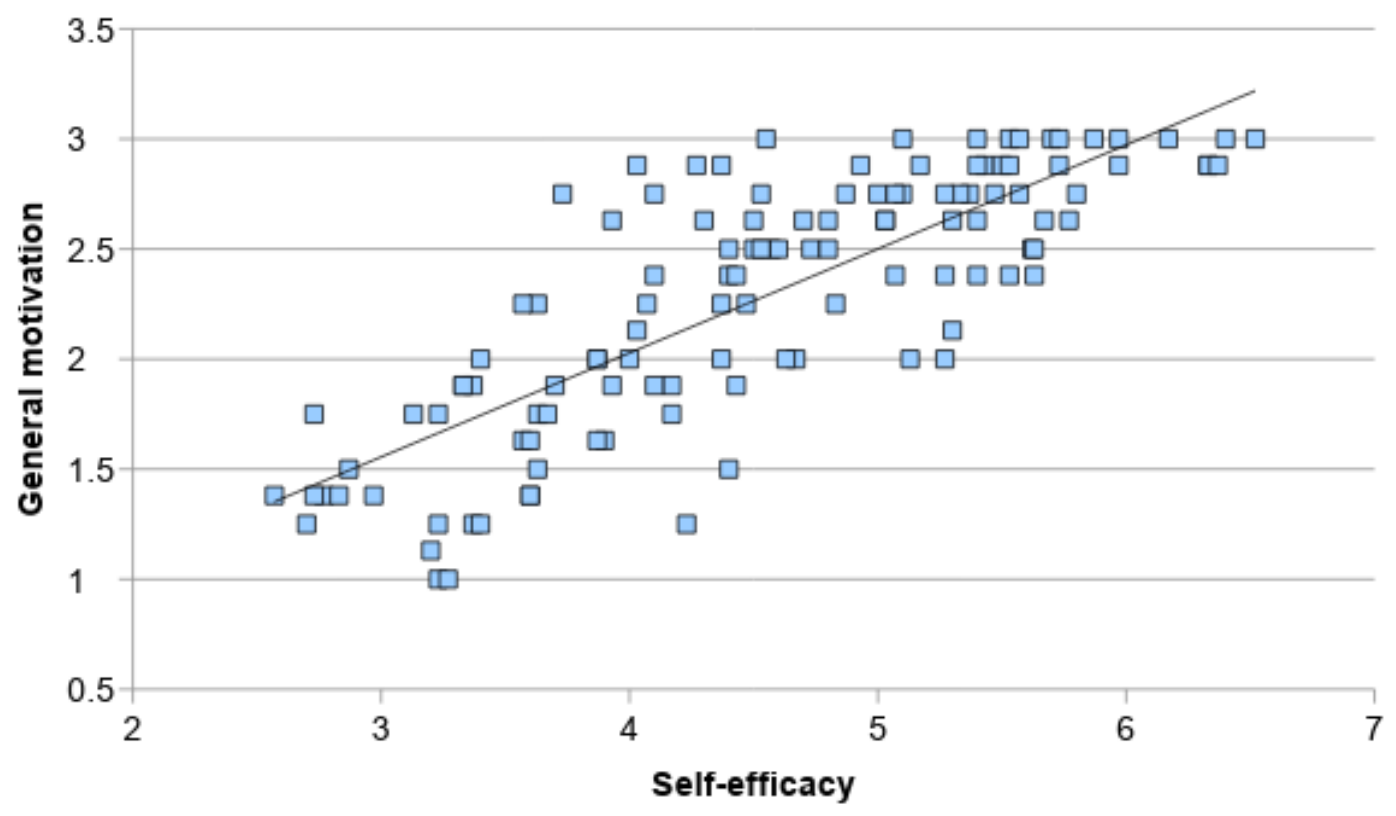

Figure 1. Linear correlation between level of self-efficacy and level of general motivation 


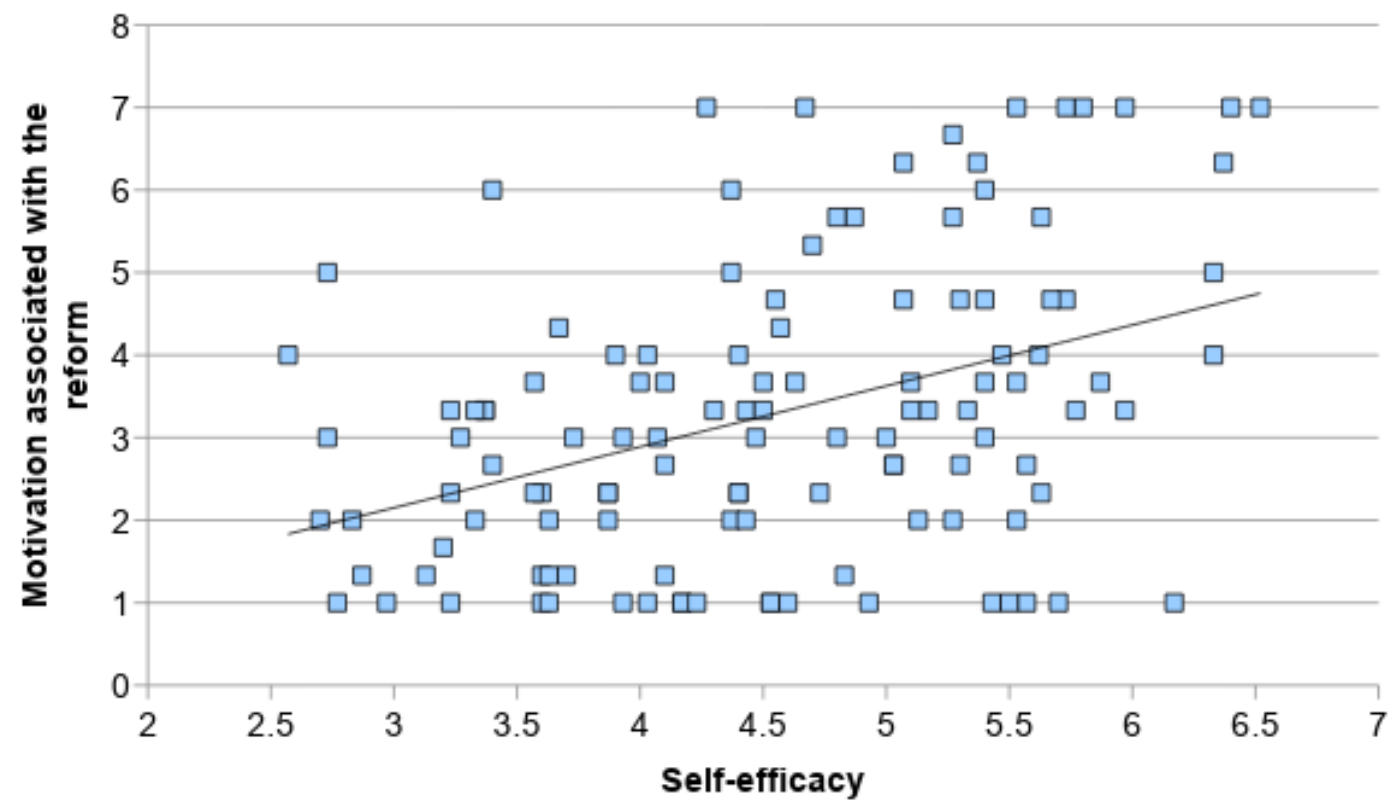

Figure 2. Linear correlation between level of self-efficacy and level of motivation associated with the reform

\subsubsection{Second Research Hypothesis: Gender Differences in the Level of Motivation and Self-Efficacy}

The second research hypothesis posited that gender differences would be found in the level of motivation and of self-efficacy. Since a significant correlation was found between the dependent variables, in order to explore this hypothesis a multiple analysis of variance was conducted. For the findings of the analysis see Table 4.

Table 4. Motivation and efficacy by students' gender: means, standard deviations, F values, and effect size $(N=120)$

\begin{tabular}{lccccccccc}
\hline & \multicolumn{2}{c}{$\begin{array}{c}\text { Female students } \\
(n=60)\end{array}$} & \multicolumn{2}{c}{$\begin{array}{c}\text { Male students } \\
(n=60)\end{array}$} & & $F_{(1,118)}$ & $p$ & $E^{2} a^{2}$ \\
\cline { 2 - 6 } & $\mathrm{M}$ & $\mathrm{SD}$ & $\mathrm{M}$ & $\mathrm{SD}$ & & & \\
\hline $\begin{array}{l}\text { Self-efficacy } \\
\text { General motivation }\end{array}$ & 2.26 & 0.54 & 2.30 & 0.60 & & 0.21 & .65 & .00 \\
$\begin{array}{l}\text { Motivation associated with the } \\
\text { reform }\end{array}$ & 4.38 & 0.94 & 4.70 & 1.00 & 3.13 & .08 & .03 \\
\hline
\end{tabular}

The table indicates gender differences in the levels of motivation and of self-efficacy. 


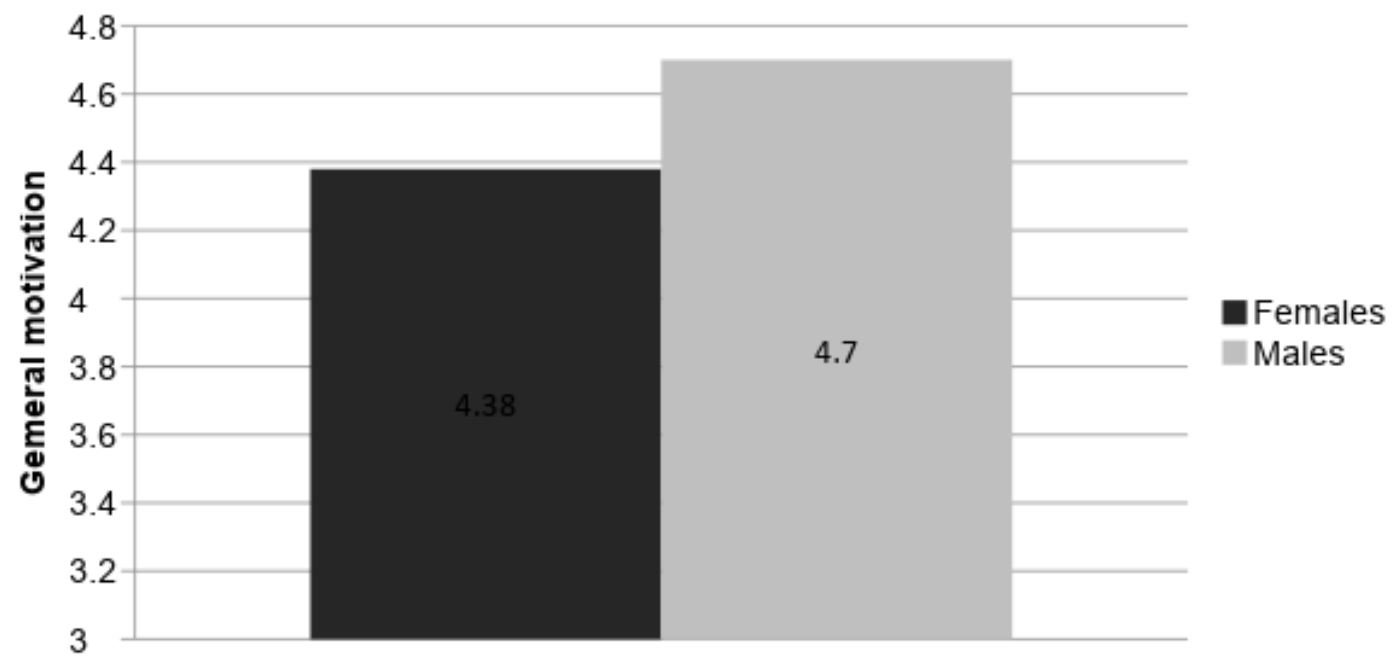

Figure 3. Gender differences in the level of general motivation

3.3.3 Third Research Hypothesis: Differences in the Level of Motivation and Self-Efficacy by Number of Matriculation Study Units in Mathematics

The third research hypothesis posited that differences would be found in the level of motivation and self-efficacy by the number of matriculation study units in mathematics. In order to explore this hypothesis, a multiple analysis of variance (MANOVA) was conducted. For the findings of the analysis see Table 5.

Table 5. Motivation and efficacy by number of math units: means, standard deviations, F values, and effect size $(N=$ 120)

\begin{tabular}{|c|c|c|c|c|c|c|c|c|c|}
\hline & \multicolumn{2}{|c|}{$\begin{array}{l}3 \text { units } \\
(n=33)\end{array}$} & \multicolumn{2}{|c|}{$\begin{array}{l}4 \text { units } \\
(n=39)\end{array}$} & \multicolumn{2}{|c|}{$\begin{array}{l}5 \text { units } \\
(n=48)\end{array}$} & \multirow[t]{2}{*}{$F_{(2,117)}$} & \multirow[t]{2}{*}{$p$} & \multirow[t]{2}{*}{$E t a^{2}$} \\
\hline & $\mathrm{M}$ & SD & $\mathrm{M}$ & SD & $\mathrm{M}$ & $\mathrm{SD}$ & & & \\
\hline Self-efficacy & 1.89 & 0.58 & 2.32 & 0.49 & 2.52 & 0.52 & 14.84 & $<.001$ & .20 \\
\hline General motivation & 3.89 & 0.78 & 4.62 & 0.84 & 4.92 & 0.99 & 13.52 & $<.001$ & .19 \\
\hline Motivation associated with the reform & 2.15 & 1.27 & 2.77 & 1.43 & 4.49 & 1.66 & 27.43 & $<.001$ & .32 \\
\hline
\end{tabular}

The following illustration summarizes the data in graphic form: 


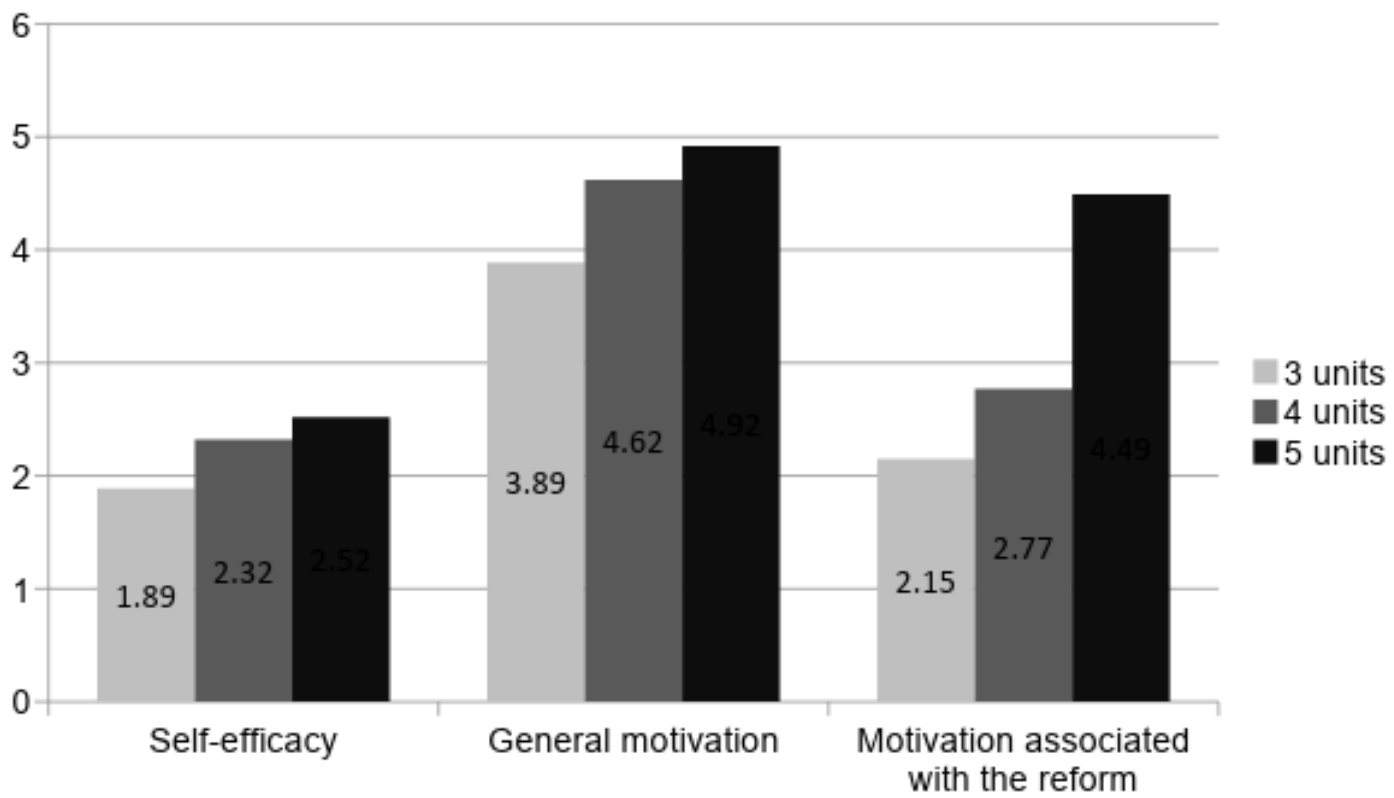

Figure 4. Differences in the level of motivation and self-efficacy by number of study units in mathematics

\section{Discussion}

The first research hypothesis posited that a positive correlation would be found between level of motivation to study mathematics and level of self-efficacy. The study found a strong significant positive correlation between level of general motivation and level of self-efficacy $(r=.81, p<.001)$, such that the higher the level of motivation the higher the level of self-efficacy. A weak-moderate significant positive correlation was found between level of motivation associated with the reform and level of self-efficacy $(r=.34, p<, 001)$, such that the higher the level of motivation associated with the reform, the higher the level of self-efficacy. In light of this, the first research hypothesis seems to have been fully confirmed (see Figures 1 and 2). Confirmation of this hypothesis corroborates previous studies on the subject, which showed that a high sense of self-efficacy is related to motivational aspects and affects the level of scholastic achievements (Zimmerman, 2006).

There is a significant difference in the power of the correlation between the level of efficacy and general motivation (items 1-31) compared to motivation associated with the reform (items 32-34). Furthermore, it is notable that the power of the first correlation (0.81) is very high. In practice, the motivation questionnaire examined not only motivation but rather also level of efficacy. When inspecting the items one by one, many questions seemed to examine the individual's belief in his ability to succeed. Such questions examine not only level of motivation rather also one's concept of efficacy. So some of the questions in the two questionnaires actually checked the same variable - and this is the reason for the strong correlation between them. In contrast, the three final questions indeed checked students' attitudes to the reform, and thus the more logical power of the correlation between this variable and efficacy.

The second research hypothesis posited that gender differences would be found in the level of motivation and self-efficacy. Examination of the general model concerning the effect of gender on self-efficacy and motivation showed no significant effect $\left(F_{(3,116)}=1.96, \mathrm{p}=.13\right.$; $\left.\mathrm{Eta}^{2}=0.05\right)$. With regard to the gender effect on each of the dependent variables, there seems to be a marginally significant effect on the level of general motivation $\left(F_{(1,118)}=3.13\right.$, $\mathrm{p}=.08$ ), such that male students were found to have a higher level of general motivation than female students (see Figure 3). No significant gender differences were found in the level of self-efficacy or motivation associated with the reform. Thus, the second research hypothesis was partially confirmed. The data of the current study confirms previous research, which indicated a trend of reduced discrepancies in math over the years between the genders in the United States (Hyde et al., 2008), both in the mean of achievements and in the different measures that reflect the rate of excelling students. For example, the rate of female students who received grades higher than 700 on the SAT in math, compared to male students, rose from 13:1 in 1983 to 3:1 in 2000 (Brody \& Mills, 2005) and a constant rise has also been recorded in the proportion of women who earn a PhD in math in the United States (Burrelli, 2008). 
The third research hypothesis posited that differences would be found in the level of motivation and self-efficacy according to the number of study units in math. The findings show significant differences in the level of efficacy between students who studied 3 units and those who studied 4 units $(p=.001)$ as well as between 3 and 5 units $(p$ $<.001$ ), such that students who studied 3 units had the lowest level of self-efficacy. In addition, no differences were found in the level of self-efficacy between students who studied 4 units and those who studied 5 units $(p=.26)$. Moreover, a similar trend was found in the level of general motivation, such that significant differences were found between students who studied 3 units and those who studied 4 units $(p=.002)$, as well as between 3 and 5 units $(p$ $<.001)$, such that students who studied 3 units had the lowest level of general motivation. In addition, no differences were found in the level of general motivation between students who studied 4 units and those who studied 5 units $(p$ $=.36$ ). Finally, significant differences were found in the level of motivation associated with Bennett's reform between students who studied 5 units and those who studied 4 units $(p<.001)$ as well as between 5 and 3 units $(p<.001)$, such that those who studied 5 units had the highest level of motivation associated with the reform. No significant differences were evident in the level of motivation associated with the reform between students who studied 3 units and those who studied 4 units $(p=.25)$. Accordingly, the third research hypothesis appears to have been confirmed. Confirmation of the research hypothesis corroborates previous studies, which showed that students' scholastic achievements in all academic subjects, including primary language and math, are affected by various personal-emotional and motivational factors (Nasser \& Birenbaum, 2005; Birenbaum \& Nasser, 2006). Also, factors such as students' self-efficacy, students' attitude to school and studies, students' diligence, students' motivation and willingness to apply themselves to their studies and to exams in general, lead to students' scholastic achievements in all subjects (Pajares \& Schnuk, 2005). Namely, the greater the differences between the unit levels in mathematics, the more success is affected by perceived self-efficacy and motivation, and therefore, students who studied 3 units had the lowest levels of self-efficacy and motivation, while among those who studied more units the aspiration to succeed together with high self-efficacy generated the ability to manage this considerable challenge. However, the reform involved 5 units while the results of the current hypothesis showed no difference in the level of self-efficacy and motivation between students who studied 4 and 5 units, questioning the demand to get students to change from 4 to 5 units, as no change is evident in their motivation and self-efficacy. These results reinforce the question of whether the transition to 5 units should not be accompanied by greater motivation and self-efficacy, or does the Ministry of Education aim for the practical level, i.e., high grades and nothing else.

Indeed, although the first hypothesis checking the association between motivation and efficacy was confirmed, and the third research hypothesis checking the association between number of units and level of motivation was confirmed as well, it is possible to make a significant distinction in analyzing these hypotheses. The research data show that the level of motivation and of self-efficacy rises by the number of units studied, such that a student studying for the 5-unit exam in math has higher motivation and a higher level of efficacy than one studying for the 3-unit exam. However, in-depth examination of the data shows that the mean of motivation associated with the reform was located slightly below the center of the scale, although the distribution of the data was heterogeneous - indicating moderate-negative attitudes to the reform. Hence, it seems that the high level of motivation and high level of self-efficacy found were not generated by the "Give Five" reform, particularly in light of the increase in the number of students studying for the 5-unit exam in math.

The program "Give Five" appears to contradict the data provided by the Ministry of Education, which show that the reform is effective. For instance, at the beginning of the reform in 2015, 11,350 students took the 5-unit matriculation exam in math, while at present, in 2018, the number of those taking the exam has risen sharply, reaching 18,500 , and the average grade was not negatively affected by this rise, remaining steady at 83 (from the Ministry of Education's website). The statements of the Ministry of Education in favor of the reform, which they say will create a "world-class power in the field of advanced technology" (Fried, Perl \& Arcavi, 2018), are proving themselves. To this must be added the research data showing that significant differences were found in the level of motivation associated with the reform, between students studying for the 5-unit exam and those studying for the 4-unit exam $(p<.001)$ and for the 3 -unit exam $(p<.001)$, such that those studying for the 5-unit exam had the highest motivation associated with the reform.

It may be said that more high school students are taking the 5-unit exam but they do not credit the reform for this. It seems that students have less faith in the reform, and the reason that more students are taking the 5-unit exam is only in order to receive bonus points ( 35 and five points for those who take the 5-unit exam), rather than based on thorough understanding of the reform's foundation and purpose. Here it is possible to ask, aside from the question of motivation and self-efficacy: Is it better in the long term for the Israeli economy that students receive a low grade in the 5-unit exam or that they study 4 units well and receive a high grade? It may be said that the outcome is important, however it 
is also possible to wonder whether in the educational system the means is not at least as important as the goal. Would it not be better to explain to the students the reason for the reform? Its essence? This might not only raise the number of students who study for more units, rather may also significantly raise their level of motivation and self-efficacy. Furthermore, there is a real opportunity to help create a generation that thinks more, understands more, that will grow up and truly succeed in all respects and not only in numbers, and this is the purpose of the current study; not only to examine the success of the reform in "cold facts", rather to examine whether aside from the improvement in students' technical data there will also be a change in their level of motivation and self-efficacy, which this study doubts.

\section{Conclusion}

It is possible to indicate several prospective research directions in order to try and increase the external validity of this study: First of all, it is important to expand this study and to include in it more heterogeneous populations, i.e., it is desirable to measure high schools from all population within the educational system, recruiting respondents from Israel's various types of high schools and sectors: secular, traditional, Arab, and Druze. Moreover, it is possible to sample respondents from schools in different parts of the country, beginning from central Israel and ending with the north and south of the country. Such research might provide a wider and more thorough picture from which it will be possible to reach conclusions that will represent a wide range of opinions with regard to the "Give Five" reform.

Another prospective study may also examine the opinions of parents and teachers with regard to the reform. Both parents and teachers are an inseparable part of the student's success or lack of success in math studies. The support of parents and teachers for understanding the significance of math is extremely important. Therefore, it is important to understand their opinion concerning the reform. For instance, if parents, teachers, and various educators will be found to believe in the success of the "Give Five" reform it will be possible to assume that they can raise students' level of motivation and self-efficacy associated with the reform, a detail that is missing in the current study. Moreover, it is possible to utilize more heterogeneous questionnaires with regard to the content of the questions and thus provide a reliable portrayal of the data without detracting from the study's discriminant validity. It may be desirable to examine in a further study the effect of providing "compensation", assuming that in such a study the research participants will complete all questions with maximum sincerity and will not hurry to submit the questionnaires. It is also possible to compare the study to others in which respondents are "not compensated" and have no motivation to complete the questionnaires in order to receive an "award" for participating in the study.

Finally, the findings of the current study were submitted to the Minister of Education who gave us the following reply:

"The revolution with regard to 5 units in mathematics is the most socially-oriented revolution to take place in Israel in recent years. Beyond the significance of excellence in mathematics, there are two major messages: the values imparted to students and the changing perception in peripheral areas. In some places in Israel no students had previously taken the 5-unit exam - in Shlomi, Rahat, and Kfar Chabad the rate was 0\%. At present, we are seeing an unprecedented leap in these places. This is a dramatic change. The students are learning that success comes from effort, persistence, and hard work - and that intelligence exists not only in the center of the country rather all over. In this way, we have managed to double the number of those taking the 5-unit matriculation exam in math to 18,050 and to give each and every one a fair point of departure and a better future.

On the gender issue, math and science are fields that for years were considered those in which boys made more of an effort, but that is of course a mistake. There is nothing a female student in Israel can wish to achieve and will not be able to. It's a question of effort and persistence, not of gender. Therefore, I'm not surprised that the level of self-efficacy is identical for the sexes, as well as motivation associated with the reform. In the national program we took a variety of actions to enhance motivation among girls, and we reached a high of 25 years (!) in the number of female students studying mathematics and in the boy-girl proportion-for the first time, the numbers are almost equal: $49 \%$ girls versus $51 \%$ boys. This is [making] history and I am very proud of it. With regard to the field of mathematics in general, I think that it will take a few more years but eventually the prevalent conception will be that success in mathematics and affiliation with this field is unrelated to the student's sex. We're already there, it only needs further establishment.

In the matter of the association between motivation and efficacy, one of the major foundations of the national program deals with encouraging and reinforcing motivation among students, nurturing their affiliation with the field, and thus empowering their faith in themselves. This finding of the study proves that our premise was correct-there is indeed an association between the student's wish to make an effort and his ability to realize in practice.

With regard to motivation by number of units, we naturally encourage the students to achieve the best matriculation certificate possible, and thus this finding is not surprising. At the same time, it is important to remember that some 
students choose to study for a 3-unit exam, it's completely legitimate, and in this setting we nurture them and encourage them to reach maximal success.

As part of the national program, we also act to advance the population of students found to have good achievements in 3 study units, to urge them to achieve a level of 4 study units, and at the same time to urge those who don't attempt the matriculation exam at all to try for a 3-unit level." (Fried, Perl \& Arcavi, 2018)

The contents of the minister's words on the gender issue are consistent with the research findings, showing that despite previous studies that indicated gender differences in math scores, these disparities are gradually diminishing and hardly constitute a discriminant factor with regard to grades, and the current study even made a new discovery that these disparities are almost nonexistent with regard to motivation and self-efficacy as well. In the matter of the association between motivation and efficacy, the minister indeed agrees that at base the program was intended to improve these areas. The research findings that show a motivation-efficacy relationship strengthen the assumption of the reform's authors while also raising the question of why the research findings show that motivation and self-efficacy are generated by the students and not related to motivation, or perhaps it may be said that although the minister identified these features as foundations of the reform, in practice the focus on grades is more central and no main emphasis is given to motivation and self-efficacy. With regard to the final finding, the minister confirms that there are differences in motivation by number of study units, which facilitates 3-unit studies and encouragement of 4-unit studies. He also insinuates that some population groups will not attempt 5 units even with the reform and therefore it is necessary to focus on helping them succeed in their current number of units, i.e., focus their motivation on their units. In other words, the 5-unit level is not appropriate for everyone and it is necessary to strengthen studies on the lower unit levels.

\section{In Summary}

The national program includes 2,000 teachers, 15 enrichment hours, and hi-tech professionals who assist the students. The program encompassed the development of 100 new tracks for 5-unit math studies throughout the country and all schools could offer 5-unit math studies - even if only a small number of students were interested. Until now opening a track required a minimum of 15 students, and from now on only six students are necessary.

The study sought to expand knowledge on the effect of students' subjective psychological feelings, such as motivation and self-efficacy, in light of the "Give Five" reform initiated by the Ministry of Education. Moreover, differences were found in the level of motivation and self-efficacy by the number of study units in mathematics. Furthermore, the gender hypothesis, also partially confirmed, contributed to the study and re-examined the accepted assumptions with regard to the various genders, as no difference was found in male and female students' level of motivation and self-efficacy. The association between self-efficacy and motivation reinforces the premises that guided the Ministry of Education in Israel, however the data showing that the reform did not lead to change in these areas may indicate that the Ministry of Education emphasizes grades and not these features.

\section{Acknowledgements}

The authors wish to thank Dvir Amar and Roei Arieli, undergraduate students of social sciences at Ariel University, for their assistance in data collection for this study.

\section{References}

Alkaabi, S., Alkaabi, W., Vyver, G. (2017). Researching Student Motivation Contemporary Issues in Education Research, 10(3), 193-202.

Amador, J. (2018). Teachers' Gender Considerations during Elementary Mathematics Lesson Design. School Science and Mathematics, 118(7), 290-299. https://doi.org/10.1111/ssm.12299

Amit, M. \& Movshovitz-Hadar, N. (1989-1990). Attribution of performance in mathematics to gender differences. Megamot, 361-373. Henrietta Szold Institute. [Hebrew]

Anderman, E.M., \& Maehr, M.L. (1994). Motivation and schooling in the middle grades. Review of Educational Research, 64, 287-309. https://doi.org/10.3102/00346543064002287

Assor, A., Roth, G., \& Deci, E.L. (2000). Sense of compulsion and sense of choice as mediators of the effects of parental strategies on children's behavior. Paper Presented at the Annual Meeting of the American Educational Research.

Bandura, A. (1977). Social learning theory. Englewood Cliffs, NJ: Prentice Hall.

Bandura, A. (1982). The assessment and predictive generality of self-precepts of efficacy. Journal of Behavior Therapy and Experimental Psychiatry, 13, 195-199. https://doi.org/10.1016/0005-7916(82)90004-0 
Bates, R., \& Khasawneh, S. (2007). Self-efficacy and college students' perceptions and use of online learning systems. Computers in Human Behavior, 23, 175-191. https://doi.org/10.1016/j.chb.2004.04.004

Beller, M., \& Gafni, N. (1996). 1991 International Assessment of Educational Progress in Mathematics and Sciences: The gender differences perspective. Journal of Educational Psychology, 88(2), 365-377. https://doi.org/10.1037/0022-0663.88.2.365

Birenbaum, M., \& Nasser, F. (2006). Ethnic and gender differences in mathematics achievement and in dispositions towards the study of mathematics. Learning and Instruction, 16, 26-40. https://doi.org/10.1016/j.learninstruc.2005.12.004

Butler, R., \& Kedar, A. (1990). Effects of intergroup competition and school philosophy on student perceptions, group processes, and performance. Contemporary Educational Psychology, 15, 301-318. https://doi.org/10.1016/0361-476X(90)90027-X

Burrelli, J. (2008). Thirty-three years of women in S\&E faculty positions, InfoBrief, Science Resources Statistics, NSF 08-308, National Science Foundation Directorate for Social, Behavioral, and Economic Sciences.

Brody, L., \& Mills, C. (2005). Talent search research: What have we learned? High Ability Studies, 16, 97-111. https://doi.org/10.1080/13598130500115320

Cave, P., Evans, N., Dewey, D., Hartshorn, K. (2018) Motivational Partnerships: Increasing ESL Student Self-Efficacy. ELT Journal, 72(1), 83-96. https://doi.org/10.1093/elt/ccx027

Chen, M., Adler, C., Levy, A. et al. (1978). The junior high research project: process and outcome in the educational act: evaluating the contribution of junior high schools to the educational system. Tel Aviv: School of Education, Tel Aviv University; and Jerusalem: Institute for the Study of Educational Nurturing, Hebrew University of Jerusalem. [Hebrew]

Dar, Y. \& Resh, N., (1981) Homogeneity and heterogeneity in education: Interaction between personal resources and the learning environment in the effect on scholastic achievement. Jerusalem: The Hebrew University, School of Education.

Deci, E.L., \& Ryan, R.M. (1985). Intrinsic motivation and self-determination in human behavior. New York: Plenum. https://doi.org/10.1007/978-1-4899-2271-7

Deloitte Haskins \& Sells (1978). The fourth directive - Company accounts. London, UK: Deloitte Haskins \& Sells.

Edwards, J.E., \& Waters, L.K. (1981). Moderating effects of achievement motivation and locus of control on the relationship between academic ability and academic performance. Educational and Psychological Measurement, 41, 585-587. https://doi.org/10.1177/001316448104100243

Ryan, R.M., \& Deci, E.L. (2000). Intrinsic and extrinsic motivations: Classic definitions and new directions. Contemporary Educational Psychology, 25, 54-67. https://doi.org/10.1006/ceps.1999.1020

English, Lyn D. (2016). Revealing and Capitalising on Young Children's Mathematical Potential. ZDM: The International Journal on Mathematics Education, 48(7), 1079-1087. https://doi.org/10.1007/s11858-016-0809-5

Farenga, S.J., \& Joyce, B.A. (1999). Intentions of young students to enroll in science courses in the future: An examination of gender differences. Science Education, 83, 55-75. https://doi.org/10.1002/(SICI)1098-237X(199901)83:1<55::AID-SCE3>3.0.CO;2-O

Fortier M.S., Vallerand R.J., Briere N.M., Provencher P.J. (1995). Competitive and recreational sport structures and gender: A test of their relationship with sport motivation. Int. J. Sport Psychol. 26, 24-26.

Fried, M., Perl, H., Arcavi, A. (2018) Chapter 1: Highlights in the Development of Education and Mathematics Education in the State of Israel: A Timeline Series on Mathematics Education, K-12 Mathematics Education in Israel, 3-19.

Goddard, R.D., Hoy, W.K., \& Woolfolk-Hoy, A. (2004). Collective efficacy: Theoretical developments, empirical evidence, and future directions. Educational Researcher, 33, 3-13. https://doi.org/10.3102/0013189X033003003

Harris, D., Black, L., Hernandez-Martinez, P., Pepin, B., Williams, J. (2015). Mathematics and Its Value for Engineering Students: What Are the Implications for Teaching? International Journal of Mathematical Education in Science and Technology, 46(3), 321-336. https://doi.org/10.1080/0020739X.2014.979893

Hendy, J., Lyons, E., \& Breakwell, G.M. (2006). Genetic testing and the relationship between specific and general self-efficacy. British Journal of Health Psychology, 11(2), 221-233. https://doi.org/10.1348/135910705X52543 
Henderson, R.W. \& Landesman, E.M. (1992). Mathematics and middle school students of Mexican descent: The effects of chemically integrated instruction.

Hornby, G., Witte, C. (2014) Ability Grouping in New Zealand High Schools: Are Practices Evidence-Based? Preventing School Failure, 58(2), 90-95.

Hutchison, M.A., Follman, D.K., Sumpter, M., \& Bodner, G.M. (2006). Factors influencing the self-efficacy beliefs of first-year engineering students. Journal of Engineering Education, 95(1), 39-47. https://doi.org/10.1002/j.2168-9830.2006.tb00876.x

Hyde, J.S., Lindberg, S.M., Linn, M.C., Ellis, A., \& Williams, C. (2008). Gender similarities characterize math performance. Science, 321, 494-495. https://doi.org/10.1126/science.1160364

Jerusalem, M., \& Schwarzer, R. (1992). Self-efficacy as a resource factor in stress appraisal processes. In R. Schwarzer (Ed.), Self-efficacy: Thought control of action (pp. 195-213). Washington, DC: Hemisphere.

Kahan, S., Linchevski, L., \& Igra, N. (1995). Ability grouping and mathematical achievements in Israeli junior high schools. Megamot, 37, 76-93. [Hebrew]

LaBone, T.R. (2007). Calculation of dose from special tritium compounds, ORAUT-OTIB0066, Revision 00, Oak Ridge Associated Universities Team, Oak Ridge, Tennessee.

Lasloy, A. \& Schwartzwold, J. (1991). Parents' considerations in choosing an educational stream for their children in elementary school. Megamot, 33, 187-204. [Hebrew]

Libao, N., Sagun, J., Tamangan, E., Pattalitan, A., Dupa, M., Bautista, R. (2016) Science Learning Motivation as Correlate of Students' Academic Performances. Journal of Technology and Science Education, 6(3) 209-218. https://doi.org/10.3926/jotse.231

Lloyd, J., \& Barenblatt, L. (1984). Intrinsic intellectuality: Its relations to social class, intelligence, and achievement. Journal of Personality and Social Psychology, 46(3), 646-654. https://doi.org/10.1037/0022-3514.46.3.646

Maccoby, E.E., \& Jacklin, C.N. (1974). The psychology of sex differences. Stanford, CA: Stanford University Press.

Maehr, M.L., \& Midgley, C. (1996). Transforming school cultures. Boulder: Westview Press.

Mason, C.L., Kahle, J.B., \& Gardner, A.L. (1991). Draw-a-scientist-test: Future implications. School Science and Mathematics, 91, 193-198. https://doi.org/10.1111/j.1949-8594.1991.tb12078.x

Mevarech, Z.R., \& Karmarski, B. (1997). Improve: A multidimensional method for teaching mathematics in heterogeneous classrooms. American Educational Research Journal, 34(2), 365-394. https://doi.org/10.3102/00028312034002365

Ministry of Education (2015). Doubling the number of students studying for five matriculation units in math. Ministry of Education website. Retrieved from http://edu.gov.il/sites/special/5/Pages/Five.html [Hebrew]

Mirza, A., Hussain, N. (2014) Motivating Learning in Mathematics through Collaborative Problem Solving: A Focus on Using Rich Tasks. Journal of Education and Educational Development, 1(1), 26-39. https://doi.org/10.22555/joeed.v1i1.13

Mukhanova, A., Mukhanov, S. (2013) Technology of design and assessment of tests in LMS Moodle (Russian: Технология проектирования и оценки тестов в СДО Moodle) Scientific Research and Their Application (Russian: Сборник научных трудов SWorld, 2013)

Nasser F., \& Birenbaum, M. (2005). Modeling mathematics achievement of Jewish and Arab eighth graders in Israel: The effects of learner-related variables. Educational Research and Evaluation, 11(3), 277-302. https://doi.org/10.1080/13803610500101108

National Science Foundation (1994). Women, minorities, and person with disabilities in science and engineering. Washington, DC: Author.

Oaks, J. (1982). The reproduction of inequity: The content of secondary school tracking. The Urban Review, 14, 107-120. https://doi.org/10.1007/BF02174647

Saunders. P. (1980). Towards a non-spatial urban sociology. Working Papers in Urban and Regional Studies, University of Sussex, 21.

Pintrich, P. \& Schunk, D. (1996). Motivation in education: Theory, research \& applications, Ch. 3. Englewood Cliffs, NJ: Prentice-Hall. 
Resh, N. \& Dar, Y. (1994). Segregation within integration: Academic separation in junior high school. Iyunim Bechinuch, 59-60, 101-123. [Hebrew]

Robbins, S.B., Lauver, K., Le, H., Davis, D., Langley, R., \& Carlstrom, A. (2004). Do psychosocial and study skills factors predict college outcomes? A meta-analysis. Psychological Bulletin, 130, 261-303. https://doi.org/10.1037/0033-2909.130.2.261

Slavin, R.E. (1990). Cooperative learning: Theory, research, and practice. Englewood Cliffs, NJ: Prentice Hall.

Usher, E.L., \& Pajares, F. (2008). Sources of self-efficacy in school: Critical review of the literature and future directions. Review of Educational Research, 78(4), 751-796. https://doi.org/10.3102/0034654308321456

Yanko, A. (2018). Who's ahead? List of outstanding high schools. Yediot Aharonoth website. Retrieved from: https://www.ynet.co.il/articles/0,7340,L-5329370,00.html. [Hebrew]

Yasar, Metin (2016) High School Students' Attitudes towards Mathematics. EURASIA Journal of Mathematics, Science \& Technology Education, 12(4), 931-945.

Zimmerman, B.J., \& Cleary, T.J. (2006). Adolescents' development of personal efficacy: The role of self-efficacy beliefs and self-regulatory skill. In F. Pajares \& T. Urdan (Eds.), Self-efficacy beliefs of adolescence (pp. 45-69). Greenwich, CT: Information Age.

Zuzovsky, R. (2003). The academic achievements of 8th graders in math and science and the educational context of their instruction in Israel (pp. 66-78). Tel Aviv: Ramot, Tel Aviv University. [Hebrew] 